\title{
The effect of aqueous extract of Allium Sativum (garlic) on erythrocyte osmotic fragility in normal and sickle cell
}

\author{
Salami Hamza Adegoke1, Gadaka Madu Adamu², John Adeolu Ige', Babagana Fatima², \\ Odirachukwu Rita ${ }^{2}$ \\ ${ }^{1}$ Department of Human Physiology, College of Medical Sciences, University of Maiduguri. Borno State, Nigeria \\ ${ }^{2}$ Department of Biochemistry, Faculty of Science, University of Maiduguri. Borno State. Nigeria
}

Email address:

adegokee2009@yahoo.com (S. H. Adegoke)

\section{To cite this article:}

Salami Hamza Adegoke, Gadaka Madu Adamu, John Adeolu Ige, Babagana Fatima, Odirachukwu Rita. The Effect of Aqueous Extract of Allium Sativum (Garlic) on Erythrocyte Osmotic Fragility in Normal and Sickle Cell. American Journal of Life Sciences.

Vol. 2, No. 5, 2014, pp. 278-281. doi: 10.11648/j.ajls.20140205.15

\begin{abstract}
Allium sativa (garlic) is a bulbous herb used as food item, spice and medicine in different parts of the world. The effect of garlic (Allium Sativa) on the osmotic fragility of red blood cells in normal and sickle cell patients was assessed in vitro. The study comprised four sets of fourteen centrifuge tubes each containing $5 \mathrm{ml}$ of graduated concentrations of normal saline. To the first set of tubes, $20 \mu \mathrm{l}$ of blood from normal subjects was added using a micropipette, while to the second, $0.75 \mathrm{mg}$ of garlic and $20 \mu \mathrm{l}$ of blood from normal subjects were added. To the third set of tubes, $20 \mu 1$ of blood from sickle cell patient was added, and to the fourth $20 \mu \mathrm{l}$ of blood from sickle cell patient and $0.75 \mathrm{mg}$ of garlic were added. Percentage hemolysis was determined by spectrophotometry. It was observed that the degree of hemolysis was greater $(\mathrm{P}<0.05)$ in the sickle cell compared to the normal blood. This observation was also recorded in the samples treated with garlic. It is concluded that the degree of hemolysis in sickle cell is higher $(\mathrm{P}<0.05)$ than normal cell. Treatment with garlic increased fragility in both normal and sickle cell blood however this effect was more pronounced in sickle cell blood. It is recommended that the consumption of garlic in patients with sickle cell anemia should be continuously monitored and carefully regulated.
\end{abstract}

Keywords: Allium Sativa (Garlic), Osmotic Fragility, Red Blood Cells, Membrane Stability, Sickle Cell Anemia, $\%$ Hemolysis

\section{Introduction}

Garlic (Allium satium) is a bulbous herb widely consumed as food, spice and medicine in various parts of the world. In Nigeria, people use it in different forms, as additive in food, soup and even eaten raw with broiled meat (suya). Therapeutic and medicinal values are also attached to allium, most of which are scientifically validated (Amagase et al, 2001; Hussein et al, 2007). Allium sativum has proven to have antiglycaemic, antidiabetic (Eidi et al, 2006), antioxidant (Dubravka and Ilona, 2003; Jaiswal and Rizvi,2011), antithrombotic (Steiner and Li, 2001; Jaiswal and Rizvi, 2011), anticarcinogenic, hepatoprotective (Hussein et al, 2007) antihypertensive, and cardioprotective activities (Singh and Singh, 2008). Phytochemical screening of Allium sativum revealed it is a rich source of important organics compound, which include steroids, saponins and flavonoids such as quercetin and kaempherol. They also are characterized by a high content of organosulphur compounds including allicin, ajoene, cephaene, zwiebalanes and $z$ propanthiol-s-oxide which are responsible for the lachrymatory pungency, typical smell and taste (Singh and Singh, 2008). More so, chronic and unregulated intake of Allium sativum was reported to cause impairment of normal red cell membrane stability in addition to an increased susceptibility to oxidative stress and formation of Heinzbody anemia. Acute toxicity studies in rodents also reveal $\mathrm{LD}_{50}$ of Allium sativum to be $3 \mathrm{~g} / \mathrm{Kg}$ body weight (Singh and Singh, 2008)

Sickle cell anemia is an inherited blood disease, in which, when red cells are deoxygenated, produce a fibrous polymer which stiffen erythrocyte membrane and alters ionic 
transport. In addition it has generally been observed that human erythrocytes are perhaps the cells most exposed to peroxidative damage by free radicals due to the high cellular concentration of oxygen and hemoglobin; a potentially powerful promoter of oxidative processes (Rother et al, 2005; Jaiswal and Rizvi, 2011) However other studies shown that the red blood cell protects itself against oxidative damage by antioxidants located in both cytosolic and membrane domains which counter the effect of antioxidant and also free radicals (Rai et al, 2009). Since previous studies (Steiner and Varga, 2003) showed the presence of both antioxidant and hemolytic agents in garlic, it will be expedient to know if normal and sickle erythrocytes have the same pattern of fragility when treated with garlic and graded concentrations of $\mathrm{NaCl}$. This work therefore compares the osmotic fragility of normal and sickle cell blood, and also the effect of garlic consumption on osmotic fragility of sickle cells and normal red blood cells with a view to evaluating the effect of antioxidants present in garlic and their role in protecting erythrocyte membrane against oxidative stress.

\section{Materials and Methods}

Plant Material: Garlic was purchased commercially and authenticated by plant taxonomist in the department of Biological science, University of Maiduguri, Nigeria.

Preparation of Garlic Extract: Fifteen grams (15g) of garlic was weighed, pulverized and mixed in $30 \mathrm{ml}$ of distilled water and passed through a Watman filter paper. The preparation served as stock solution and was kept at $20^{\circ} \mathrm{C}$.

\section{Subject and Blood Sample Collection}

A total of 10 subjects comprising 5 sickle cell patients with hemoglobin SS and 5 normal subjects with hemoglobin AA of both sexes and in different ages were randomly recruited into the study. Five milliliter $(5 \mathrm{ml})$ of blood sample was collected from each sickle cell subject and $10 \mathrm{ml}$ from normal subjects aseptically for the determination of osmotic fragility. Genotypes were determined to ensure the hemoglobin genotype was AA in normal and SS in sickle cell subjects respectively. The blood was collected using sterile EDTA vacutainers from a peripheral vein and carefully mixed. All blood samples were collected between 9 am and $12 \mathrm{pm}$. The collected blood was immediately analyzed to determine erythrocyte osmotic fragility of each blood sample.

In vitro erythrocyte osmotic fragility was evaluated in normal and sickle erythrocyte using the method described by Faulknet and King (1970) using graded concentrations of sodium chloride $(0.2-1.0 \%)$ at physiological $\mathrm{pH}$ (7.4). Four sets of fourteen (14) centrifuge tubes (1-14) each containing $5 \mathrm{ml}$ of graded normal saline with concentrations $0.2-1.0$ were prepared. To the first set of tubes containing graded normal saline, $20 \mu \mathrm{L}$ of fresh blood from normal subjects was added to each test tube using a micro-pipette, while to the second set, $20 \mu \mathrm{L}$ of sickle cell fresh blood was added. To the third set, $20 \mu \mathrm{L}$ of sickle cell blood and $0.75 \mathrm{mg}$ of garlic was added while to the fourth set $20 \mu \mathrm{L}$ of normal blood and $0.75 \mathrm{mg}$ of garlic was added. The content was mixed by inverting the tube and then centrifuged at 1500 R.P.M. for 10 minutes. The supernatants were transferred into glass curvettes and the absorbance of the supernatants were measured colorimetrically using a Corning colorimeter 252 (Corning Ltd. ALSTEAD, Esex England) at 540nm wavelength. The percentage hemolysis for each sample was calculated and plotted against sodium chloride concentration.

Thus, percentage hemolysis:

$$
\text { Haemolysis }(\%)=\frac{\text { Optical Density of Test Solution }}{\text { Optical Density of Standard Solution }} * 100
$$

\section{Statistical Analysis}

Values expressed as mean \pm SEM were subjected to one way analysis of variance (ANOVA) and Turkey test using GraphPad version 4.0 for Windows from GraphPad software, San Diego, California, U.S.A (www.graphpad.com). Values of $\mathrm{P}<0.05$ were considered significant.

\section{Results}

The osmotic fragility of erythrocytes from normal and sickle cell subjects before and after treatment with garlic are presented in Table 1. It was observed that fragility of red cells decreased as the concentration of $\mathrm{Nacl}$ increases from $0.20 \mathrm{gm} \%$ to $1 \mathrm{gm} \%$ in all four groups studied. The decrease in the fragility was significantly $(\mathrm{P}<0.05)$ higher in normal blood at each grade of concentration compared to sickle cell blood. There was complete hemolysis at $0.20 \mathrm{gm} \%$ of $\mathrm{Nacl}$ in sickle and normal blood cells. However, at $0.75 \% \mathrm{Nacl}$, cessation of hemolysis was observed in normal blood cells, a phenomenon that was not the case in sickle cell blood, as hemolysis continued at all concentrations of $\mathrm{NaCl}$ and stabilized at mean percentage hemolysis of $2.29 \pm 0.45$ (Table 1, Fig 1). The results also showed a significant increase $(\mathrm{P}<0.05)$ in osmotic fragility of red cells treated with garlic in both normal and sickle cell samples, though it was more pronounced in sickle compared to normal cells. The analysis of the result also showed a significant decrease $(\mathrm{P}<0.05)$ in osmotic fragility of treated normal red cells in interval II $(0.55-0.75 \% \mathrm{NaCl})$, while in the same interval the osmotic fragility of sickle cell blood treated with garlic was significantly higher $(\mathrm{P}<0.05)$ compared to normal cells treated with garlic. This observation was also made in interval III of osmotic fragility curve (Fig 2). 
Table 1. Osmotic Fragility of Normal and Sickle Cells and the Effect of Garlic on Fragility of Normal and Sickle cells.

\begin{tabular}{lllll}
\hline \multirow{2}{*}{ NaCl (\%) } & \multicolumn{2}{l}{ Mean \pm SEM \% Fragility } & & Sickle Blood with Garlic \\
\cline { 2 - 5 } & Normal Blood & Normal Blood with Garlic & Sickle Blood & $100 \pm 0.00$ \\
0.20 & $100 \pm 0.00$ & $100 \pm 0.00$ & $100 \pm 0.00$ & $100 \pm 0.00$ \\
0.30 & $85.6 \pm 1.78$ & $100 \pm 0.00$ & $100 \pm 0.00$ & $100 \pm 0.00$ \\
0.40 & $83.8 \pm 1.88$ & $88.0 \pm 0.02$ & $96.4 \pm 0.68$ & $100 \pm 0.00$ \\
0.50 & $79.8 \pm 2.87$ & $80.0 \pm 1.02$ & $85.6 \pm 1.78$ & $100 \pm 0.00$ \\
0.55 & $72.0 \pm 0.89$ & $76.2 \pm 1.28$ & $79.8 \pm 2.87$ & $100 \pm 0.00$ \\
0.60 & $2.6 \pm 0.24$ & $10.2 \pm 0.01$ & $38.6 \pm 0.60$ & $92.6 \pm 1.66$ \\
0.65 & $2.0 \pm 1.05$ & $6.4 \pm 0.01$ & $32.4 \pm 0.24$ & $75.0 \pm 4.29$ \\
0.70 & $1.2 \pm 1.20$ & $3.3 \pm 0.24$ & $25.8 \pm 0.49$ & $45.0 \pm 0.20$ \\
0.75 & $0.0 \pm 0.00$ & $0.37 \pm 0.01$ & $2.29 \pm 0.45$ & $41.0 \pm 0.45$ \\
0.80 & $0.0 \pm 0.00$ & $0.37 \pm 0.01$ & $2.29 \pm 0.45$ & $40.2 \pm 0.25$ \\
0.85 & $0.0 \pm 0.00$ & $0.37 \pm 0.01$ & $2.29 \pm 0.45$ & $37.6 \pm 0.81$ \\
0.90 & $0.0 \pm 0.00$ & $0.37 \pm 0.01$ & $2.29 \pm 0.45$ & $30.3 \pm 0.23$ \\
\hline
\end{tabular}

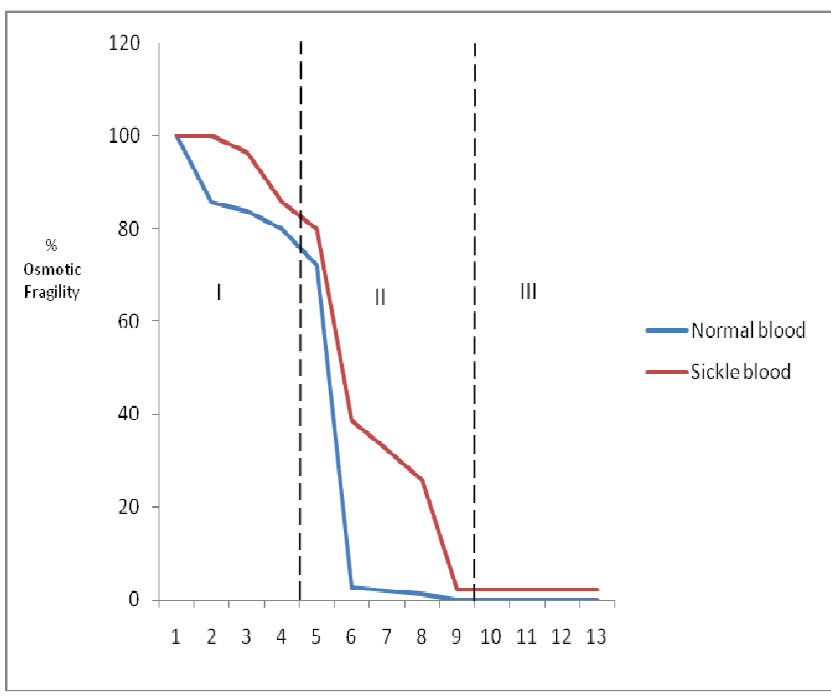

Fig. 1. Osmotic Fragility of Normal and Sickle Blood.

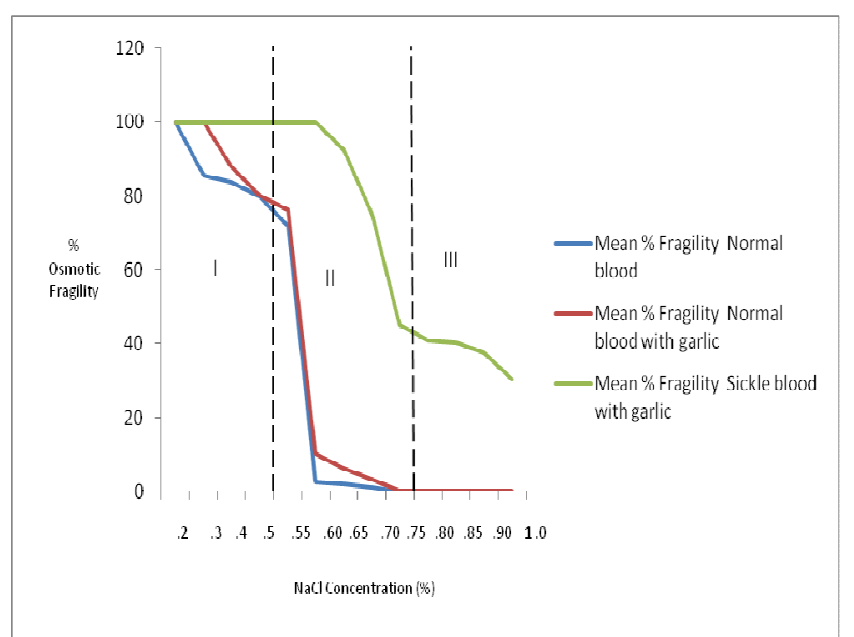

Fig. 2. The Effect of Treatment with Garlic on Osmotic Fragility of Normal and Sickle Cells.

\section{Discussion}

Osmotic fragility of erythrocytes demonstrates the integrity of red cell membranes in pathological and normal states (Rai et al, 2009). The present results obtained from osmotic fragility tests of sickle cell blood showed increased fragility compared to normal red blood cells. Although the exact mechanism was not demonstrated in this study, our findings support the view of previous researches that demonstrated the occurrence of intravascular hemolysis of sickle cell blood (Rother et al, 2005; Nolan et al, 2005). The intravascular hemolysis according to their findings was attributed to polymerization, which subsequently leads to irreversible sickling of these cells as well as oxidative damage which compromises cell integrity and cause hemolysis (Kato et al, 2009). An increased sickle cell susceptibility to lysis increases free heme and heme degradation products in the plasma (Silva et al, 2013). This theory is supported by an increased osmotic fragility of sickle cells reported in this study. Other studies suggest that there is increased Heinz body formation resulting from impaired pentose phosphate shunt activity. Heinz bodies form islands within the cytoplasm as well as adhere to the erythrocyte membrane, thereby increasing their rate of destruction (Takasu et al, 2006). Also, prior to the collection of sickle cell blood, it is possible that these cells have been subjected to polymerization and oxidative damage that might directly cause high levels of hemolysis. This supports the higher degree of fragility observed in sickle cells as compared to normal erythrocytes in this study. In order to gain insight into whether sickle cells have already undergone multiple cycles of sickling and unsickling which may have damaged the cell membranes in vivo, a comparative study was carried out between normal red cell with hemoglobin AA and sickle cell with hemoglobin SS after subjecting both types of red cells to a natural hemolytic agent such as allium cepa in vitro as described by previous studies in rats (Salami et al, 2012). Our result showed that irrespective of red cell type, exposure to allium cepa enhance lysis, and as expected the percentage of lysis is higher in sickle cell blood than normal red cells, thus suggesting rigidity of sickle cells as well as previous in vivo polymerization and oxidative damage which might be a contributive factor to the high degree of haemolysis recorded in sickle cells before it was collected.

In summary: 
(1) The observed increase osmotic fragility in sickle cells compared to normal blood could be an indication of intravascular damage and release of hemoglobin otherwise the same pattern of fragility should be recorded in sickle and normal cells upon subjecting these cells to the same physiological salt solutions.

(2) A substantial amount of intravascular partial damage is likely to have occurred in vivo in sickle cell hemoglobin polymers. This is evidenced by the dramatic increase in fragility upon subjecting both normal blood cells with homozygous AA and sickle cell homozygous SS to herbal haemolytic agent such as allium.

\section{Conclusion}

It can be concluded from this study that osmotic fragility of sickle cells is higher than normal cells. There is enough evidence to show that exposure to raw garlic cause further increase in hemolysis of sickle cells. Ingestion of raw allium should be closely monitored or discouraged as food or treatment for ailments in people with sickle cell diseases.

\section{References}

[1] Amagase H., Petsech B.L., Mansuura H. (2001): Intake of garlic and its bioa-ctive components. Journal of Nutrition.131: 9555-9625.

[2] Dubravka S. and Ilona S.V. (2003): An Evolution of the Antioxidant Abilities of Allium Species. Acta Biol Szeged. 47(1-4): 103-106.

[3] Eidi A., Eidi M., ESMALILI E. (2006): Antidiabetic Effect of Garlic (Allium sativum L) in Normal and Streptozotocin Induced Diabetic Rats. Phytomed 13(9-10): 624-629.

[4] Faulknet W.R., King J.W (1970): Manual of Clinical Laboratory Procedures. Clevland $\mathrm{OH}$ : Chemical Rubber Company.

[5] Hussein, J.S, Ovaby, F.S and El Shatey N. (2007): Anti Hepatotoxic Effect of Garlic and Onion Oils on Ethanol-
Induced Liver Injury in Rats. J of Appl Sci Res. 3(11): 152753.

[6] Jaiswal N. and Rizvi I.S. (2011); Protective Effect of Different Layers of Onion Extracts (Allium Cepa L.) on Markers of Oxidative Stress in Erythrocytes. Cell Memb. Free Rad. Res. 3(2): 171-177

[7] Kato G.I., Gladwin M.T. (2009) Mechanism and Clinical Complications of Hemolysis in Sickle Cell Disease and Thalassemia. In Steinberg M.H., Forget B.G., Higgs D.R., Nagel R.I. editors: Disorders of Hemoglobin Genetic, Pathophysiology and Clinical Management. New York Cambridge University Press.

[8] Nolan. V.G., Wyszynski D.F., Farrer L.A., Steinberg M.H., (2005) Hemolysis-associated Priapism in Sickle Cell Disease. Blood 106(9): 3264-3267.

[9] Rai, D.K., Rai P;K., Rizui S., Watal G., Shama B., (2009): . Carbofuran Induced Toxicity in Rats: Protective Role of Vitamin C. Experimental Toxicology and Pathology. 612531 535.

[10] Rother R.P., Bell., Hillmen P., Gladwin M.T., (2005): The Clinical Sequelae of Intravascular Hemolysis and Extra Cellular plasma Hemoglobin. A novel Mechanism of Human Disease. JAMA J. American Medical Association 295(13): 1653-1662.

[11] Salami H.A., Ekanem A.U. and John A.I., (2012): The Effect of Aqueous Preparation of Allium Cepa (Onion) and Allium Sativa (Garlic) on Erythrocyte Osmotic Fragility in Wistar Rats: In Vivo and In Vitro Studies. Nig. J. Physiol. Sci. 27(1): 29-34.

[12] Silva H.G.D., Junior B.E., Almeida A.E. and BoniniDomingos R.C. (2013): Oxidative Stress in Sickle Cell Disease: An Overview of Erythrocyte Redox Metabolism and Current Antioxidant Therapeutic Strategies. Free Rad. Biol. Med. 65: 1101- 1109.

[13] Singh V. K., Singh D.K (2008): Pharmacological Effects of Garlic (Allium sativum L.). Annu Rev Biomed Sci; 10:6-26.

[14] Steiner M., and Li W. (2001): Garlic as an Antithrombotic Agent. J. Nutri. 131(35): 980-984.

[15] Takasu J., Uykimpang R., Sunga M. A., Amagase H. and Niihara Y. (2006): Aged Garlic Extract is a Potential Therapy for Sickle Cell Anemia. J. Nutr. 803S-805S. 